\title{
CARACTERIZAÇÃO QUÍMICA DE FRUTOS DE JENIPAPEIROS NATIVOS DO RECÔNCAVO BAIANO VISANDO AO CONSUMO NATURAL E INDUSTRIALIZAÇÃ̃ ${ }^{1}$
}

\author{
DANIELADE SOUZA HANSEN² ${ }^{2}$ SIMONEALVES SILVA ${ }^{3}$, ANTONIO AUGUSTO OLIVEIRAFONSECA ${ }^{4}$, \\ ORLANDO ANTONIO DE SOUZA HANSEN ${ }^{5}$, NATIANA OLIVEIRAFRANÇA $^{5}$
}

RESUMO-O objetivo deste trabalho foi identificar a variabilidade química de frutos de jenipapeiro com potencial econômico para o Recôncavo Baiano. Foram identificadas 100 árvores de jenipapeiro distribuídas em seis municípios do Recôncavo Baiano, onde se coletaram 10 frutos por planta para realização das análises químicas. As variáveis estudadas foram: pH, teor de sólidos solúveis (SS), ácido ascórbico (AA), acidez titulável (AT), relação entre sólidos solúveis e acidez titulável (SS/AT), açúcares redutores (AR), nãoredutores (ANR) e totais (AST). Para a interpretação dos resultados, utilizaram-se análise descritiva e coeficiente de Correlação de Pearson. As análises dos frutos nas safras de 2004/2005 apresentaram valores médios iguais a 3,44 e 3,39 para o pH; 1,40\% e 1,42\% de AT; $17,18^{\circ}$ Brix e $16,8^{\circ}$ Brix para SS; $2,76 \mathrm{mg} .100 \mathrm{~g}^{-1}$ e $2,65 \mathrm{mg} .100 \mathrm{~g}^{-1}$ de ácido ascórbico; $9,26 \%$ e 8,95\% de AR; 3,39\% e 3,31\% de ANR; $12,61 \%$ e $12,28 \%$ de AST; 12,37 e 12,00 para SS/AT. Os resultados permitiram concluir que existe variabilidade para os caracteres analisados, possibilitando a exploração econômica dos frutos para o consumo in natura e industrialização; que o SS contribui para a maioria dos caracteres, com exceção da vitamina C, e os genótipos $\mathrm{JP}_{12}, \mathrm{JP}_{39} \mathrm{JP}_{41}, \mathrm{JP}_{59}, \mathrm{JP}_{73}, \mathrm{JP}_{79}, \mathrm{JP}_{80} \mathrm{JP}_{83}, \mathrm{JP}_{89}, \mathrm{JP}_{90}$ e $\mathrm{JP}_{99}$ podem ser recomendados para utilização nas condições agroecológicas do Recôncavo Baiano.

Termos para indexação: Genipa americana L., qualidade, caracterização genética, composição química.

\section{CHEMICAL CHARACTERIZATION OF NATIVE JENIPAPO FRUITS FROM THE RECÔNCAVO BAIANO REGION AIMING IN NATURA FRUIT CONSUMPTION AND INDUSTRIALIZATION}

\begin{abstract}
The objective of the present work was to identify the variability in the chemical constituents of jenipapo fruit with economic potential for the Recôncavo Baiano Region. One-hundred jenipapo fruit trees, distributed in six counties of the Recôncavo Baiano Region region, were identified and 10 fruit per plant were collected for the chemical analyses. The variables studied were: $\mathrm{pH}$, soluble solids (SS), ascorbic acid content (AA), titrable acidity (TEA), soluble solids and titrable acidity ratio (SS/TEA), reducing sugars (RS), non-reducing sugars (NRS) and total sugars (TS). Descriptive analysis and the Pearson correlation coefficient were used in order to interpret the data. The fruit analysis in the 2004/2005 harvest period presented average values equal to 3.44 and $3.39 \mathrm{for} \mathrm{pH}$;

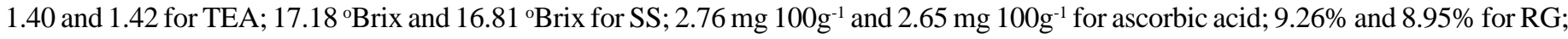
$3.39 \%$ and $3.31 \%$ for NRG; $12.61 \%$ and $12.28 \%$ for TG; 12.37 and 12.00 for SS/TEA. The results concluded that there is variability for the characteristics analyzed, enabling the economic exploration of the fruits for in natura consumption as well as industrialization, and the genotypes JP ${ }_{12}, \mathrm{JP}_{39}, \mathrm{JP}_{41}, \mathrm{JP}_{59}, \mathrm{JP}_{73}, \mathrm{JP}_{79}, \mathrm{JP}_{80}, \mathrm{JP}_{83}, \mathrm{JP}_{89}, \mathrm{JP}_{90}$, and $\mathrm{JP}_{99}$, can be recommended to the agro-ecological conditions of the Recôncavo Baiano region.
\end{abstract}

Index Terms: Genipa americana L., quality, characterization genetic, chemical composition.

\section{INTRODUÇÃO}

A fruticultura brasileira apresenta grande importância, não somente no setor primário, mas também para a indústria e o comércio. É uma atividade importante na fixação do homem à terra, pois possibilita uma exploração intensiva das áreas de produção; utiliza uma elevada quantidade de mão-de-obra, constituindo em expressiva fonte geradora de empregos; proporciona a obtenção de produtos de alto valor agregado, tanto em frutas destinadas ao consumo in natura quanto industrializadas (Hoffmann et al., 1996).
As frutas são alimentos que oferecem grande variedade de sabores e aromas, sendo compostas basicamente de água, açúcares (sacarose, glicose e frutose, entre outros), vitaminas e sais minerais. Além de energéticas, são portadoras de propriedades medicinais, estimulando as funções gastrointestinais (Lima, 1998).

O consumo de produtos naturais tem crescido rapidamente, principalmente os que utilizam frutas como base para a produção de alimentos, como iogurtes, sorvetes, bolos, pães e cereais. Para que um alimento possa ser aceito pelo consumidor, várias características que determinam sua qualidade

'(Trabalho 231-07). Recebido em: 27-09-2007. Aceito para publicação em:27-08-2008.

${ }^{2}$ Eng. Agrônoma, M.Sc. em Ciências Agrárias, hansen@ufrb.edu.br

${ }^{3}$ Eng. Agrônoma, Professora Dra. do Centro de Ciências Agrárias, Ambientais e Biológicas da Universidade Federal do Recôncavo da Bahia, sas@ufrb.edu.br ${ }^{4}$ Eng. Agrônomo, Professor M.Sc. do Centro de Ciências Exatas e Tecnológicas da Universidade Federal do Recôncavo da Bahia, aaugusto@ufrb.edu.br ${ }_{5}^{5}$ Acadêmicos do curso de Engenharia Agronômica do Centro de Ciências Agrárias, Ambientais e Biológicas da Universidade Federal do Recôncavo da Bahia.

Rev. Bras. Frutic., Jaboticabal - SP, v. 30, n. 4, p.964-969, Dezembro 2008 
devem ser satisfeitas. Essas características estão relacionadas ao conjunto de atributos referentes à aparência, sabor, odor, textura e valor nutritivo, relacionados com a caracterização física e química dos frutos (Chaves, 1993).

Os dados de composição de alimentos são úteis na elaboração de dietas para indivíduos, na avaliação do estado geral de saúde de uma população, na relação entre o estado de saúde com determinadas doenças, para planejamento governamental a fim de que uma política agropecuária seja estabelecida, bem como para pesquisas e desenvolvimento de indústrias na área alimentícia (Lajolo \& Vanucchi, 1987; Lajolo, 1995).

As regiões Norte e Nordeste do Brasil, pelas condições climáticas, produzem grande número de frutos tropicais com perspectivas para exploração econômica (Arckoll, 1997). Giacometti (1993) relata que a região Nordeste, em especial, temse destacado pelo elevado número de empresas de processamento de polpa de frutas, mas devido à dificuldade na obtenção de matérias-primas relacionadas a algumas espécies existe uma grande dificuldade para a manutenção do pleno funcionamento destas empresas. Dentre as inúmeras espécies frutíferas utilizadas pela população nordestina, destaca-se o jenipapeiro (Genipa americana L.), cuja comercialização como fruta fresca tem-se revelado promissora, sendo realizada nas feiras livres, nos mercados atacadistas e em supermercados. A industrialização, sob as mais diferentes formas, tem estimulado bastante o crescimento da demanda dos frutos pelo mercado nordestino, com possibilidade de expansão para outras regiões brasileiras ou mesmo para o mercado internacional (Prudente, 2002).

De acordo com Santos (2001), analisando frutos de jenipapo na região de Cruz das Almas-BA, os valores encontrados na constituição química foram: $\mathrm{pH} 3,60$; sólidos solúveis 18,34 ${ }^{\circ}$ Brix; acidez titulável 1,66\%; açúcares totais $15,69 \%$; umidade $73,75 \%$; cinzas $1,22 \%$, e relação sólidos solúveis com acidez titulável de 11,58. Figueiredo (1984), em estudos com a mesma frutífera no município de Maranguape, no Ceará, verificou que o conteúdo em ferro foi de $0,80 \mathrm{mg} \cdot 100 \mathrm{~g}^{-1}$, cálcio $45,82 \mathrm{mg} \cdot 100 \mathrm{~g}^{-1}$, fósforo $33,50 \mathrm{mg} .100 \mathrm{~g}^{-1}$, fibras $2,03 \%$ lipídios $0,35 \%$, e proteína $0.68 \%$. Para Franco (1992), o valor energético do jenipapo é de 81,70 calorias, e as seguintes vitaminas podem ser encontradas em sua composição: A (30 mg.100g $\left.\mathrm{g}^{-1}\right), \mathrm{B} 1\left(24 \mathrm{mg} \cdot 100 \mathrm{~g}^{-1}\right)$, B2 $(275$ mg. $\left.100 \mathrm{~g}^{-1}\right)$ e C $\left(6,80 \mathrm{mg} \cdot 100 \mathrm{~g}^{-1}\right)$.

$\mathrm{Na}$ escolha de um genótipo, espera-se que sua superioridade inicial permaneça constante durante todo o seu ciclo e que o bom desempenho manifestado em certas estruturas, ou em partes integrantes do indivíduo, reflita o potencial do genótipo a ser utilizado como um todo (Cruz \& Regazzi, 1997). No entanto, os resultados obtidos com a caracterização de frutos em níveis regionais não podem ser extrapolados de uma região para outra, devido aos atributos de qualidade sofrerem influência do clima, solo, tratos culturais e estádio de maturação (Nascimento et al., 1991). Diante do exposto, o objetivo deste trabalho foi identificar a variabilidade química de frutos de jenipapeiro com potencial econômico para o Recôncavo Baiano.

\section{MATERIAL E MÉTODOS}

O estudo foi realizado em seis populações de Genipa americana L., localizadas nos municípios de Cruz das Almas, Governador Mangabeira, Cabaceiras do Paraguaçu, Muritiba, Sapeaçu e Conceição do Almeida, no Estado da Bahia. A região situa-se no Recôncavo Baiano, localizado entre $12^{\circ} 23^{\prime}$ e $13^{\circ} 24^{\prime}$ de latitude sul e $38^{\circ} 38^{\prime}$ e $40^{\circ} 10^{\prime}$ de longitude oeste, o que lhe confere características de clima tropical. A maior parte dos solos da região é do grupo Latossolo e Argissolo, de baixa fertilidade. A pluviosidade é de 1.100 a $2.000 \mathrm{~mm}$ de chuvas anuais, a temperatura média acima de $18^{\circ} \mathrm{C}$ e o relevo basicamente modelado em tabuleiros (Rezende, 2004).

No período da safra de jenipapo na região, nos meses de maio a junho, dos anos de 2004 e 2005, foram identificados com auxílio de GPS (Sistema de Posicionamento Global), 100 genótipos de jenipapeiro distribuídos aleatoriamente nas populações.

De cada planta, foram coletados 10 frutos, no estádio "de vez" (maturo), nos quatro quadrantes da copa, formando-se amostras compostas para a realização da caracterização química. Em jenipapo, segundo observação em campo, os frutos colhidos no estádio "de vez", apesar de possuírem polpa firme, cedem à pressão quando comprimidos levemente, não havendo nenhuma alteração quanto à coloração que ajudasse a definir o seu estádio fisiológico.

Os frutos colhidos foram acondicionados em sacos plásticos e transportados ao Laboratório de Tecnologia de Alimentos do Centro de Ciências Agrárias, Biológicas e Ambientais da Universidade Federal do Recôncavo da Bahia, no município de Cruz das Almas, onde permaneceram sob condições ambiente, e à medida que foram atingindo a maturação (aproximadamente 3 dias após a coleta), realizou-se a higienização para caracterização química. Foram utilizadas três repetições de três frutos por amostra, nas seguintes análises: $\mathrm{pH}$, determinado com o auxílio do potenciômetro aferido à temperatura de $25^{\circ} \mathrm{C}$ e calibrado com solução-tampão 4,0 e 7,0; sólidos solúveis (SS), por meio de leitura em refratômetro e os resultados expressos em ${ }^{\circ}$ Brix, e teor de ácido ascórbico (AA) utilizando a metodologia do iodeto de potássio, conforme Instituto Adolf Lutz (1985); acidez titulável (AT) expressa em percentual de ácido tartárico, relação entre sólidos solúveis e acidez titulável (SS/AT), açúcares redutores (AR), não-redutores (ANR) e totais (AST), conforme recomendação da AOAC (1975).

Para a interpretação dos resultados, utilizaram-se análise descritiva de estimativa da média, desvio-padrão e coeficiente de variação, sendo as médias originais comparadas pelo valor da média geral mais ou menos um desvio-padrão. Os valores encontrados acima da média mais um desvio padrão foram classificados como superiores. A relação existente entre os caracteres estudados foi estimada por meio do coeficiente de Correlação de Pearson e a hipótese de que o coeficiente de correlação é igual a zero, foi avaliada pela estatística t, com um nível de significância de $5 \%$. 


\section{RESULTADOS E DISCUSSÃO}

O conhecimento sobre as correlações fenotípicas entre caracteres de frutos de importância econômica é muito utilizado em trabalhos de melhoramento genético, pois permite conhecer a influência que a seleção em uma característica terá sobre outras, aparentemente independentes. As Tabelas 1 e 2 apresentam os resultados de correlação fenotípicas para as variáveis químicas em jenipapeiros, onde se observa certa estabilidade nos dois anos de estudo, evidenciando que a seleção de genótipos superiores pode ser realizada independentemente do ano de colheita.

Houve associação positiva e significativa entre sólidos solúveis (SS) com açúcares redutores (AR), não-redutores (ANR) e totais (AST), indicando que frutos com maior teor de SS possuem também maior conteúdo em açúcares. Este fato já era esperado, uma vez que os sólidos solúveis em sucos de frutas representam a percentagem de sacarose, outros açúcares e sais dissolvidos (Hoffmann et al., 1996). Desta forma, para o comércio ao natural ou para o processamento industrial, espera-se um elevado conteúdo em sólidos solúveis devido à preferência dos consumidores por frutos doces e a eficiência do processo industrial. A acidez desejável em frutos dependerá do destino que lhe será dado, pois frutos com menor acidez são os indicados para satisfazer as exigências do consumidor brasileiro ao consumir a fruta ao natural, enquanto os de maior acidez são recomendados para a industrialização (Botrel, 1994). Wong (1995) relata que a comercialização de frutos de jenipapo segue algumas exigências relacionadas à sua composição química, e para atender a elas, os frutos de jenipapo necessitam possuir teores de sólidos solúveis entre 18 e $20^{\circ}$ Brix, 1,0 a 2,0 mg de ácido ascórbico/ 100g de polpa, e acidez titulável entre 0,20 e $0,40 \%$.

A relação entre sólidos solúveis e acidez titulável (SS/ AT) é o parâmetro mais importante para se determinar a maturação e o que melhor informa sobre a palatabilidade dos frutos (Chitarra \& Chitarra, 1990). Geralmente, os consumidores brasileiros preferem uma elevada relação SS/AT, sendo comum encontrar elevados teores de sólidos solúveis nesta situação. A relação SS/AT apresentou correlação positiva e significativa com sólidos solúveis; $\mathrm{pH}$; açúcares redutores (AR), não-redutores (ANR) e totais (AST). O pH está relacionado à conservação dos alimentos, atividade enzimática, textura de geléias e gelatinas, retenção do sabor-odor de produtos de frutas, estabilidade de corantes artificiais em produtos de frutas, e verificação do estado de maturação das frutas (Cecchi, 2003). Assim, nas correlações fenotípicas positivas e significativas, os caracteres podem ser considerados uma única unidade de seleção, enquanto nas correlações negativas, há dificuldade em selecionar, simultaneamente, os caracteres superiores.

$\mathrm{Na}$ Tabela 3, encontramos os resultados referentes à análise química em frutos de jenipapo envolvendo 100 genótipos de populações naturais. Os resultados obtidos para coeficiente de variação permaneceram semelhantes nos dois anos de estudo, sendo a menor variação observada para o $\mathrm{pH}, 3,08 \%$ e $2,20 \%$ respectivamente, enquanto a máxima variação foi para o teor de ácido ascórbico (AA), 36,51\% e 33,72\%.
$\mathrm{O}$ pH encontrado nas diferentes populações variou de 3,01 a 3,68 no primeiro ano de estudo, enquanto no ano subseqüente foi de 3,22 a 3,60 . As médias obtidas nos dois anos foram de 3,44 e 3,39, apresentando valores semelhantes aos encontrados por Santos (2001) e Fonseca et al. (2003), com a mesma fruteira e na mesma região (3,65 e 3,52, respectivamente). Valores mais altos de $\mathrm{pH}$ (baixa acidez) são preferidos para o consumo in natura, porém constitui-se em problema para a indústria devido ao favorecimento das atividades enzimáticas e desenvolvimento de microrganismos. A Indústria de Alimentos utiliza o efeito do $\mathrm{pH}$ sobre os microrganismos para a preservação dos alimentos, sendo o $\mathrm{pH}=4,5$ muito importante, pois abaixo desse valor não há o desenvolvimento de Clostridium botulinum bem como, de forma geral, das bactérias patogênicas. Em alimentos muito ácidos ( $\mathrm{pH}<4,0)$, a microbiota capaz de se desenvolver é restrita apenas aos bolores e leveduras, e, por vezes, bactérias lácticas e acéticas (Hoffmann, 2001). Os genótipos avaliados apresentaram $\mathrm{pH}$ interessante para a indústria de processamento de frutas, podendo também ser utilizados como fonte de frutos para o consumo in natura.

Os valores médios para a acidez total (AST), nas duas safras estudadas, foram de $1,40 \%$ e $1,42 \%$, não variando muito de um ano para o outro. Em trabalhos realizados por diversos autores, foram encontrados valores iguais a 1,66\% (Santos, 2001), 1,64\% (Fonseca et al., 2003), 0,127\% (Silva et al., 1998) e 0,94\% (Figueiredo, 1984). Quando a acidez de produtos destinados à industrialização é baixa, há um aumento nos gastos da empresa com a adição de acidulantes. O ácido cítrico é o mais utilizado pela indústria de frutas devido à alta solubilidade e ao seu efeito tamponante, que favorece a estabilidade dos produtos finais; por isso, é bastante comum no preparo de geléias, doces em massa e frutas em calda (Torrezan et al., 1999).

O conteúdo de SS variou de $8,73^{\circ}$ Brix a $23,20{ }^{\circ}$ Brix no primeiro ano de estudo, e $12,20^{\circ} \mathrm{Brix}$ a $23,73^{\circ} \mathrm{Brix}$ no segundo ano. As médias foram de $17,18^{\circ}$ Brix e $16,81^{\circ}$ Brix, apresentando valores semelhantes aos de outras fruteiras nativas potenciais, como bacuri $16,40^{\circ}$ Brix (Manica, 2000), mangaba $16.72^{\circ}$ Brix (Moura et al., 2003), ciriguela $16.90^{\circ}$ Brix (Filgueiras et al., 2000) e cupuaçu $16.37^{\circ}$ Brix (Schwan et al., 2000). Os melhores resultados dentro das safras avaliadas foram encontrados nos genótipos $\mathrm{JP}_{12}, \mathrm{JP}_{41}$, $\mathrm{JP}_{79}, \mathrm{JP}_{83}$ e $\mathrm{JP}_{99}$ (Tabela 4); no entanto, todos apresentam valores satisfatórios para o consumo in natura e industrial.

A variação no teor de ácido ascórbico foi de 1,25 mg.100g ${ }^{-1}$ a $5,93 \mathrm{mg} .100 \mathrm{~g}^{-1}$ e $1,18 \mathrm{mg} \cdot 100 \mathrm{~g}^{-1}$ a $5,51 \mathrm{mg} \cdot 100 \mathrm{~g}^{-1}$, respectivamente, para os dois anos de estudo. As médias foram de $2,76 \mathrm{mg} .100 \mathrm{~g}^{-1}$ e $2,65 \mathrm{mg} .100 \mathrm{~g}^{-1}$, destacando-se como superiores os genótipos $\mathrm{JP}_{11}\left(4,50 \mathrm{mg} \cdot 100 \mathrm{~g}^{-1}\right)$, JP${ }_{25}(5,21$ mg.100g $\left.{ }^{-1}\right), \mathrm{JP}_{27}\left(3,90 \mathrm{mg} .100 \mathrm{~g}^{-1}\right), \mathrm{JP}_{64}\left(5,31 \mathrm{mg} .100 \mathrm{~g}^{-1}\right)$, $J_{69}\left(5,72 \mathrm{mg} .100 \mathrm{~g}^{-1}\right), \mathrm{JP}_{82}\left(4,81 \mathrm{mg} .100 \mathrm{~g}^{-1}\right), \mathrm{JP}_{83}(5,33$ mg.100g $\left.{ }^{-1}\right), \mathrm{JP}_{87}\left(3,95 \mathrm{mg} .100 \mathrm{~g}^{-1}\right), \mathrm{JP}_{88}\left(4,00 \mathrm{mg} .100 \mathrm{~g}^{-1}\right)$, $\mathrm{JP}_{90}\left(3,81 \mathrm{mg} .100 \mathrm{~g}^{-1}\right)$ e $\mathrm{JP}_{92}\left(5,40 \mathrm{mg} .100 \mathrm{~g}^{-1}\right)$. O teor de vitamina $\mathrm{C}$ presente naturalmente nas frutas é um parâmetro nutricional de grande importância, porém não se verificam exigências relacionadas ao mesmo no caso de frutas destinadas à industrialização, por isso pode ser considerado um parâmetro tecnológico dispensável (De Marchi et al., 2000). 
Nas safras de 2004/2005, os valores médios para açúcares redutores foram de $9,26 \%$ e $8,95 \%$, enquanto para não-redutores de $3,39 \%$ e $3,31 \%$. A média para açúcares totais foi de $12,61 \%$ e $12,28 \%$, destacando-se com os melhores percentuais os genótipos $\mathrm{JP}_{39}, \mathrm{JP}_{59}, \mathrm{JP}_{73}, \mathrm{JP}_{80}, \mathrm{JP}_{89}, \mathrm{JP}_{90}$ e $\mathrm{JP}_{99}$ A relação SS/AT apresentou valores médios iguais a 12,37 e 12,00 , relativos às safras avaliadas, sendo o melhor desempenho observado em $\mathrm{JP}_{39}, \mathrm{JP}_{59}, \mathrm{JP}_{73}, \mathrm{JP}_{89}, \mathrm{JP}_{90}$ e JP $\mathrm{Jg}_{99}($ Tabela 4).

TABELA 1 - Estimativas dos coeficientes de correlação de Pearson (r) entre os pares de caracteres químicos de frutos de 100 genótipos de jenipapeiros nativos do Recôncavo Baiano, 2004.

\begin{tabular}{|c|c|c|c|c|c|c|c|c|}
\hline & $A A$ & $A T$ & $P H$ & $S S$ & $A R$ & $A N R$ & $A S T$ & $S S / A T$ \\
\hline \multicolumn{9}{|l|}{ AA } \\
\hline AT & $-0,0433$ & & & & & & & \\
\hline $\mathrm{pH}$ & $-0,1134$ & $-0,3051^{*}$ & & & & & & \\
\hline SS & 0,0207 & $0,3401 *$ & 0,1005 & & & & & \\
\hline$A R$ & 0,0284 & $0,2346^{*}$ & 0,0797 & $0,8054^{*}$ & & & & \\
\hline$A N R$ & 0,0489 & $0,2533^{*}$ & 0,0804 & $0,7780 *$ & $0,6811^{*}$ & & & \\
\hline$A S T$ & 0,0317 & $0,2739 *$ & 0,0873 & $0,8832 *$ & $0,8690 *$ & $0,7749 *$ & & \\
\hline$\underline{S S / A T}$ & 0,0564 & $-0,4540 *$ & $0,3115^{*}$ & $0,6710^{*}$ & $0,5513^{*}$ & $0,5196^{*}$ & $0,5927^{*}$ & \\
\hline
\end{tabular}

* nível de significância a 5\%. AA - ácido ascórbico $\left(\mathrm{mg}^{1} 100 \mathrm{~g}^{-1}\right)$, AT - acidez titulável (\%), SS - sólidos solúveis ( ${ }^{\circ}$ Brix), AR - açúcares redutores (\%), ANR - açúcares não-redutores (\%), AST - açúcares totais (\%), SS/AT - relação sólidos solúveis e acidez titulável.

TABELA 2 - Estimativas dos coeficientes de correlação de Pearson (r) entre os pares de caracteres químicos de frutos de 100 genótipos de jenipapeiros nativos do Recôncavo Baiano, 2005.

\begin{tabular}{|c|c|c|c|c|c|c|c|c|}
\hline & $\boldsymbol{A} \boldsymbol{A}$ & $A T$ & $P H$ & $S S$ & $A R$ & $A N R$ & $A S T$ & $S S / A T$ \\
\hline \multicolumn{9}{|l|}{$\mathbf{A A}$} \\
\hline AT & $-0,0601$ & & & & & & & \\
\hline pH & 0,0228 & $-0,2886^{*}$ & & & & & & \\
\hline SS & 0,1342 & $-0,0046$ & 0,0622 & & & & & \\
\hline$A R$ & 0,1402 & $-0,0089$ & 0,0618 & 0,9993* & & & & \\
\hline$A N R$ & 0,1191 & 0,0226 & 0,0439 & $0,9913 *$ & $0,9868^{*}$ & & & \\
\hline$A S T$ & 0,1296 & $-0,0135$ & 0,0711 & $0,9979 *$ & $0,9972 *$ & 0,9901 * & & \\
\hline$S S / A T$ & 0,1372 & $-0,6729 *$ & $0,2750 *$ & $0,7284^{*}$ & $0,7302 *$ & $0,7046^{*}$ & $0,7345^{*}$ & \\
\hline
\end{tabular}

* nível de significância a $\mathbf{5 \%}$. AA - ácido ascórbico $\left(\mathrm{mg}^{1} 100 \mathrm{~g}^{-1}\right)$, AT - acidez titulável (\%), $\mathbf{S S}$ - sólidos solúveis ('Brix)AR - açúcares redutores (\%), ANR - açúcares não-redutores (\%), AST - açúcares totais (\%), SS/AT - relação sólidos solúveis e acidez titulável.

TABELA 3 - Caracterização química de frutos de 100 genótipos de jenipapeiro nativos do Recôncavo Baiano, 2004/2005.

\begin{tabular}{lcccccccc}
\hline \multirow{2}{*}{ Genótipos } & $\mathbf{p H}$ & $\mathbf{A T}$ & $\mathbf{S S}$ & $\mathbf{A A}$ & $\mathbf{A R}$ & ANR & AST & SS/AT \\
\cline { 2 - 8 } & & & & & & & & \\
\hline Média & 3,42 & 1,41 & 16,99 & 2,70 & 9,11 & 3,35 & 12,45 & 12,18 \\
DP & 0,09 & 0,18 & 2,31 & 0,95 & 1,09 & 0,40 & 1,46 & 2,04 \\
CV\% & 2,64 & 12,72 & 13,63 & 18,62 & 11,07 & 11,79 & 11,78 & 16,71 \\
Min. & 3,11 & 1,05 & 10,46 & 1,22 & 6,53 & 2,30 & 8,93 & 7,48 \\
Máx. & 3,64 & 1,95 & 23,46 & 5,72 & 12,25 & 4,60 & 16,37 & 18,29 \\
\hline
\end{tabular}

Média de 9 frutos por genótipo. AT - acidez titulável (\%), SS - sólidos solúveis ( $\left.{ }^{\circ} B r i x\right)$, AA - ácido ascórbico (mg.100g-1 $)$, AR - açúcares redutores (\%), ANR - açúcares não-redutores (\%), AST - açúcares totais (\%), SS/AT - relação sólidos solúveis e acidez titulável. 
TABELA 4 - Resultados médios da caracterização química dos genótipos superiores analisados nos anos de 2004/2005 nas condições agroecológicas do Recôncavo Baiano.

\begin{tabular}{|c|c|c|c|c|c|c|c|c|}
\hline \multirow[b]{2}{*}{ Genótipos } & \multicolumn{8}{|c|}{ Caracteres } \\
\hline & pH & AT & SS & $\mathbf{A A}$ & $\mathbf{A R}$ & ANR & AST & SS/AT \\
\hline JP12 & 3,38 & 1,44 & 19,73 & 2,95 & 10,11 & 3,75 & 14,4 & 13,63 \\
\hline JP39 & 3,52 & 1,10 & 16,60 & 2,03 & 8,79 & 3,26 & 12,59 & 14,78 \\
\hline JP41 & 3,43 & 1,64 & 19,76 & 1,71 & 10,50 & 3,89 & 13,96 & 12,03 \\
\hline JP59 & 3,55 & 1,54 & 23,46 & 2,71 & 11,44 & 4,59 & 16,37 & 15,23 \\
\hline JP73 & 3,35 & 1,24 & 19,03 & 3,34 & 10,04 & 3,72 & 13,62 & 15,29 \\
\hline JP79 & 3,38 & 1,38 & 19,53 & 3,35 & 12,26 & 3,82 & 14,35 & 14,14 \\
\hline JP80 & 3,44 & 1,23 & 17,96 & 2,45 & 9,56 & 3,93 & 13,74 & 14,48 \\
\hline JP83 & 3,51 & 1,39 & 19,56 & 5,33 & 10,43 & 3,78 & 13,47 & 14,06 \\
\hline JP89 & 3,45 & 1,27 & 20,00 & 2,78 & 10,66 & 3,75 & 14,59 & 15,19 \\
\hline JP90 & 3,35 & 1,11 & 18,26 & 3,81 & 9,75 & 3,61 & 12,86 & 16,38 \\
\hline JP99 & 3,43 & 1,14 & 19,53 & 1,97 & 10,43 & 3,65 & 14,25 & 16,93 \\
\hline Média & 3,44 & 1,32 & 19,40 & 2,95 & 10,36 & 3,80 & 14,02 & 14,74 \\
\hline DP & 0,07 & 0,18 & 1,69 & 1,02 & 0,92 & 0,32 & 1,00 & 1,33 \\
\hline CV\% & 1,99 & 13,49 & 8,70 & 34,59 & 8,92 & 8,38 & 7,17 & 9,03 \\
\hline Min. & 3,35 & 1,10 & 16,60 & 1,71 & 8,79 & 3,26 & 12,59 & 12,03 \\
\hline Máx. & 3,55 & 1,64 & 23,46 & 5,33 & 12,26 & 4,59 & 16,37 & 16,93 \\
\hline
\end{tabular}

Média de 9 frutos por genótipo. AT - acidez titulável (\%), SS - sólidos solúveis ( ${ }^{\circ}$ Brix), AA - ácido ascórbico (mg.100g-1 $)$, AR - açúcares redutores (\%), ANR - açúcares não-redutores (\%), AST - açúcares totais (\%), SS/AT - relação sólidos solúveis e acidez titulável.

\section{CONCLUSÕES}

1-Existe variabilidade para os caracteres analisados, possibilitando a exploração econômica dos frutos para o consumo in natura e industrialização.

2-O conteúdo de sólidos solúveis contribui para a maioria dos caracteres, com exceção do ácido ascórbico.

3-Os genótipos $\mathrm{JP}_{12}, \mathrm{JP}_{39}, \mathrm{JP}_{41}, \mathrm{JP}_{59}, \mathrm{JP}_{73}, \mathrm{JP}_{79}, \mathrm{JP}_{80}, \mathrm{JP}_{83}, \mathrm{JP}_{89}$, $\mathrm{JP}_{90}$ e $\mathrm{JP}_{99}$, de acordo com os resultados nas safras avaliadas, são recomendados para utilização nas condições agroecológicas do Recôncavo Baiano.

\section{AGRADECIMENTOS}

Os autores agradecem à Fundação de Amparo à Pesquisa do Estado da Bahia (FAPESB), pelo financiamento do trabalho, e à CAPES, pela concessão da bolsa de mestrado.

\section{REFERÊNCIAS}

ARCKOLL, D. B. Some lesser-known Brazilian fruits unexploited commercial potential. In: INTERNATIONAL SYMPOSIUM OF THE INTERNATIONAL FEDERATIONOF FRUIT JUICE PRODUCERS, 19., 1997, Den Haag. Proceedings... Den Haag: International Federation of Fruit Juice Producers, 1997. p. 27-34.

ASSOCIATION OF OFFICIAL ANALYTICAL CHEMISTS. Official methods of analysis of the AOAC. $12^{\text {th }}$ ed. Washington D.C, 1975. p. 391-410.

BOTREL, N. Manga: variedades, qualidade e tecnologia pós- colheita. Informe Agropecuário. Belo Horizonte, v.17, n. 179, p. 55-60, 1994.

CECCHI, H. M. Fundamentos teóricos e práticos em análise de alimentos. 2. ed. Campinas- SP: Editora da UNICAMP, 2003. 107 p.

CHAVES, J. B. P. Análise sensorial: histórico e desenvolvimento. Viçosa-MG: Imprensa Universitária, 1993. 31 p. (Práticas de laboratório, n. 338).

CHITARRA, M. I. F.; CHITARRA, A. D. Pós-colheita de frutos e hortaliças, fisiologia e manuseio. Lavras: ESAL/FAEPE, 1990. $239 \mathrm{p}$.

CRUZ, C. D.; REGAZZI, A. J. Modelos biométricos aplicados ao melhoramento genético. 2. ed. Viçosa, MG: Universidade Federal de Viçosa, 1997. 390p.

DE MARCHI, R.; MONTEIRO, M.; BENATO, E. A.; Silva, A. R. da. Uso da cor da casca como indicador de qualidade do maracujáamarelo (Passiflora edulis Sims. f. flavicarpa Deg.) destinado à industrialização. Ciência e Tecnologia de Alimentos, Campinas, v. 20, n.3, p. 381-387, 2000 .

FIGUEIREDO, R. W. Estudo de industrialização do jenipapo (Genipa americana L.). 1984. 171 f. Dissertação (Mestrado em Tecnologia de Alimentos) - Universidade Federal do Ceará, Fortaleza. 1984.

FILGUEIRAS, H. A. C.; MOURA, C. F. H.; ALVES. R. E. Ciriguela (Spondias purpúrea L.). In: ALVES, R.E.; FILGUEIRAS, H.A.C.; 
MOURA, C.F.H. (Ed.). Caracterização de frutas nativas da América Latina. Jaboticabal: Funep, 2000. 66 p.

FONSECA, A. A. O.; CALAFANGE, P. L. P.; HANSEN, D. de S.; DANTAS, A. C. V. L.; SANTOS, M. B. dos. Caracterização física, química e físico-química dos frutos de 12 genótipos de jenipapeiros no Recôncavo Baiano. In: CONGRESSO BRASILEIRO DE MELHORAMENTO DE PLANTAS, 2., 2003, Porto Seguro. Anais... Porto Seguro: SBMP, 2003. CD-ROM.

FRANCO, G. Tabela de composição química de alimentos. Rio de Janeiro: Atheneu, 1992. 307 p.

GIACOMETTI, D. C. Recursos genéticos de fruteiras nativas do Brasil. In: SIMPÓSIO NACIONAL DE RECURSOS GENÉTICOS DE FRUTEIRAS NATIVAS, 1993, Cruz das Almas. Anais... Cruz das Almas: Embrapa- CNPMF, 1993. p. 13-27.

HOFFMANN, A.; NACHTIGAL, J. C.; KLUGE, R. A.; FACHINELLO, J. C. Adubação em pomares: métodos de quantificação das doses de fertilizantes. Revista Brasileira de Fruticultura, Jaboticabal, v.18, n. 2, p. 161-169, 1996.

HOFFMANN, F. L. Fatores limitantes à proliferação de microorganismos em alimentos. Brasil Alimentos, São Paulo, v. 9, n. 1, p.23-30, 2001.

INSTITUTO ADOLFO LUTZ. Normas analíticas do Instituto Adolf Lutz: métodos químicos e físicos para análises de alimentos. 2. ed. São Paulo: Instituto Adolfo Lutz, 1985. v.1, 533p.

LAJOLO, F. M. Grupo de trabalho: composição de alimentos. Boletim da Sociedade Brasileira de Ciência e Tecnologia de Alimentos, Campinas, v. 29, n. 1, p. 57-69, 1995.

LAJOLO, F. M.; VANUCCHI, H. Tabelas de composição de nutrientes em alimentos, situação no Brasil e necessidades. Archivos Latino-americanos de Nutrição, Caracas, v. 37, n. 4, p. 703-713, 1995.

LIMA, U. de A. Agroindustrialização de frutas. São Paulo: EALQ. 1998. $151 \mathrm{p}$.

MANICA, I. Frutas nativas, silvestres e exóticas. 1: técnicas de produção e mercado: abiu, amora-preta, araçá, bacuri, biribá, carambola, cereja-do-rio-grande, jabuticaba. Porto Alegre: Cinco Continentes, 2000.327p.

MOURA, N. F.; REZENDE, C. F. A.; NAVES, R. V.; CHAVES, J. L.; AGUIAR, A. V.; MOURA, M. F. Estrutura espacial da variabilidade genética de populações naturais de mangabeira (Hancornia speciosa Gomes) no Cerrado. In: SIMPÓSIO BRASILEIRO SOBRE A CULTURA DA MANGABA, 2003, Aracaju. Anais... Embrapa-CPATC, 2003. CD-ROM.

NASCIMENTO, L. M. do; SANTOS, R. R. dos; RIBEIRO, I. J. A.; MARTINS, F. P.; YOTSUYANAGI, K.; COUTINHO, J. R. Caracterização físico-química dos frutos de 22 cultivares de goiabeiras (Psidium guajava L.) durante o processo de maturação. Revista Brasileira de Fruticultura, Jaboticabal, v.13, p. 35-42, 1991.

PRUDENTE, R. M. Jenipapo (Genipa americana L.). In: VIEIRA NETO, R. D. Fruteiras potenciais para os tabuleiros costeiros e baixadas litorâneas. Aracajú: Embrapa-CPATC/Emdagro, 2002. p. $88-114$.

REZENDE, J. de O. Recôncavo Baiano, berço da Universidade Federal segunda da Bahia: passado, presente e futuro. Salvador: P\&A, 2004. 194 p.

SANTOS, R. O. S. Caracterização de jenipapeiros (Genipa americana L.) em Cruz das Almas-BA. 2001. 70 f. Dissertação (Mestrado em Ciência Agrárias) - Escola de Agronomia, Universidade Federal da Bahia, Salvador, 2001.

SCHWAN, R. F.; SOUZA, S. M. M. de; MENDONÇA, M. A. S. Cupuaçu (Willd ex spreng schum). In: ALVES, R.E.; FILGUEIRAS, H.A.C.; MOURA, C.F.H. (Ed.). Caracterização de frutas nativas da América Latina. Jaboticabal: Funep, 2000. 66 p.

SILVA, A. P. da; LIMA, C. L. C. de; VIEITES, R. L. Caracterização química e física do jenipapo (Genipa americana $\mathrm{L}$.) armazenado. Scientia Agrícola, Piracicaba, v. 55, n. 11, p. 29-34. 1998.

TORREZAN, R.; JARDINE, J. G.; VITALI, A. de A. Efeito da adição de solutos e ácidos em polpa de goiaba. Ciência e Tecnologia de Alimentos, Campinas, v. 19, n. 1, p. 43-45, 1999.

WONG, S. W. S. Química de los alimentos: mecanismos y teoria. Zaragoza: Acribia, 1995. 475p. 